
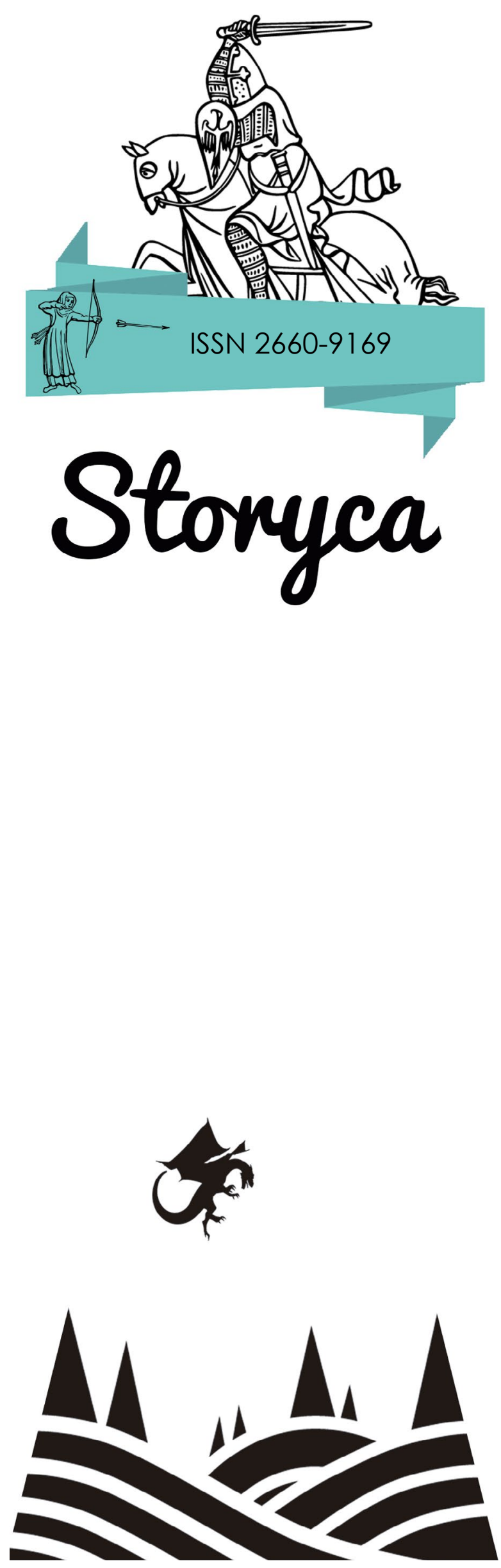

\section{Un deber de vindicta que atraviesa los siglos: La crónica de Leodegundo}

Gaspar Meana
Ya han transcurrido 15 años desde que terminé la última viñeta de La crónica de Leodegundo y no sé si me asombra más que haya podido terminarla y editarla pese a las dificultades o que vaya quedando tan atrás. Con todo, ahora que se me pide que le dedique unas palabras, aún me causa más perplejidad comprender que ya pasa del medio siglo el tiempo en que comenzó a gestarse, porque todo empezó siendo yo aún un niño.

Todavía me veo en la lejana infancia apacentando distraídamente el ganado de unos parientes maternos en la ladera de Parres que se precipita hacia el viejo puente del Sella, admirándome de que en aquella diminuta Cangas que veía al fondo del valle hubiesen bullido reyes con sus ejércitos doce siglos atrás. La mente de un crío inquieto puede maquinar diabluras para huir de la quietud y el tedio, así que me preguntaba cómo habrían sido su apariencia, su palacio, sus miedos o sus actos. Una curiosidad que no tenía modo se saciar, lo que todavía resultaba más estimulante.

Ni que decir tiene que apenas tuve oportunidad comencé a informarme en la medida de mis posibilidades. Primero a través de los historiadores de prestigio, pero luego también 


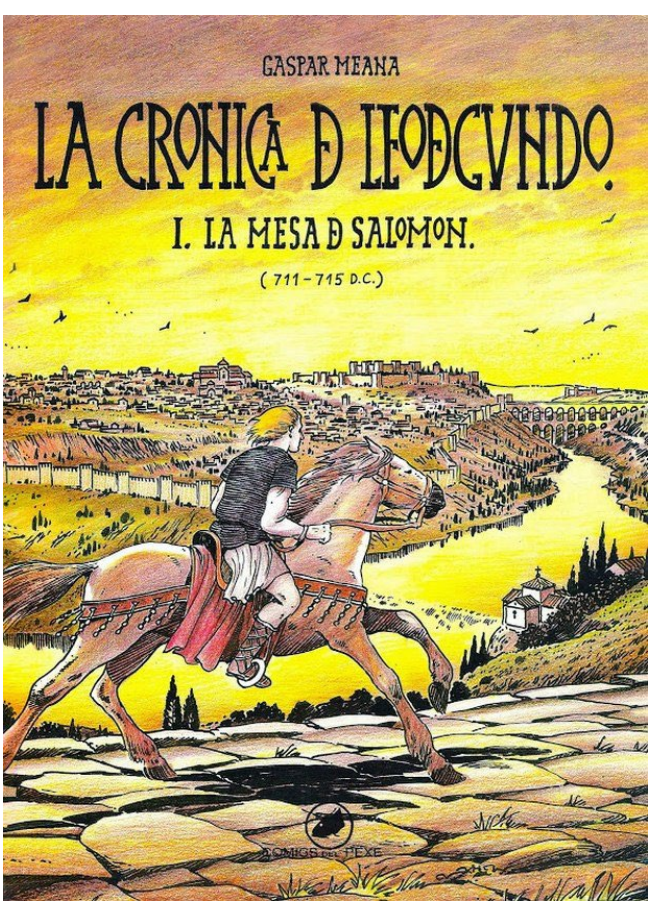

La Mesa de Salomón [711-715 d. C.] (El Cantar de Liuva), Gaspar Meana a través de sus fuentes, y así hasta que cumplí la treintena, que fue cuando me decidí a llevar al cómic todo el bagaje acumulado. Para entonces los libros más manoseados y anotados de mi incipiente biblioteca ya eran las Crónicas asturianas editadas en 1985 por la Universidad de Oviedo, la Crónica del 754 editada por López Pereira en Zaragoza (1980) o el Ajbar Machmúa y la Crónica del moro Rasis, en sendas ediciones facsímiles que pude adquirir con ímprobos esfuerzos en mis primeros viajes a Madrid en una mítica y ya desaparecida librería de la calle Claudio Coello.

Solo cuando empecé a escribir el guion comprendí que había tomado la decisión de avance hacia un terreno muy pantanoso. Todas las contradicciones internas del ciclo cronístico de Alfonso III debían dirimirse o desecharse según el caso y con presteza, pues el tiempo apremiaba si quería llevar a término una obra que se adivinaba larga y onerosa. Y por si esta dificultad de partida fuera pequeña, estaban las noticias de los textos árabes, que en no pocas ocasiones entraban en colisión dramática con sus hermanas septentrionales. De todo aquel barullo de afirmaciones poco verosímiles por exageradas o directamente mendaces surgió la pretensión de elaborar un relato contestatario y rupturista con la visión tradicional de los acontecimientos. En realidad no podía proponerse otra cosa alguien convencido de que Alfonso III mentía cuando le escribió a Sebastián de Salamanca que le remitía la historia que otros no habían querido escribir «por pereza» o porque prefirieron «ocultar en el silencion.' Sabedor de que sí se había escrito Historia antes en la corte (Bronisch, 2009), este modo de pronunciarse me pareció un desafío imposible de resistir: ¿qué había querido ocultar aquel rey aficionado a las crónicas? Con esta cuestión por divisa comenzaron a fluir a mi mente diversas posibilidades hasta que comprendí que lo que el astuto monarca intentaba solapar era un conflicto tan grave y antiguo como su propia corona, que dificultaba en grado máximo su programa unificador neogoticista, una contienda dilatada en el tiempo que debía obviar con tacto porque a sus venas habían venido a confluir a partes iguales las sangres de los dos partidos enfrentados: ¡A este conflicto se debía que ya hacia el inicio del Reino de Asturias unos hubiesen dado en afirmar que a un mero espatario lo elevaron por rey los astures y otros dijesen que unos godos de sangre real que no estuvieron presentes en tal proclamación escogieron a uno de los suyos! Merced a este hallazgo comprendí quiénes habían contendido. Habían entrado a rivalizar de un lado una dinastía emergente que tomó las riendas de su destino a raíz de que la realeza

1. Véase la Crónica de Alfonso III. Versión A. Sebastián la en Crónicas Asturianas, Oviedo, Universidad de Oviedo, 1985, p. 195. 
goda pactase con los enemigos de Cristo y dejase de defender a la Iglesia y, de otro, la antigua casa real que nunca aceptó sinceramente las críticas, que jamás estuvo dispuesta a dejarse superar por los arribistas Pelágidas y que no tardó en utilizar las peores armas para evitar su relegación.

Por desgracia, aunque las propuestas ñoñas y mentirosas de la casa Chindasvindiana jamás me engañaron, no pude sortear el fracaso, pues el entramado de falsificaciones era sólido y los historiadores inconformistas como Luis Agustín García Moreno apenas habían empezado a desenredarlo. De ahí que aunque mis propósitos estuviesen bien enderezados, mi reconstrucción de la caída del reino godo de Toledo y los albores del asturiano deje bastante que desear. De hecho, si pudiese rehacerla sería muy distinta.

Solo me consuela un poco pensar que de haber aguardado a tener mis conocimientos actuales la obra no habría visto nunca la luz. Pero ¿̇cómo iba a poder discernir con apenas 30 años que las noticias cordobesas sobre los inicios del reino astur no merecían más crédito que las que legó la corte de Oviedo? ¿Cómo iba a saber en aquel entonces que la historiografía musulmana había tardado más de 100 en interesarse por las razones del derrumbe de la monarquía hispánica, cuando ya hacía muchas décadas que habían muerto todos sus protagonistas? ¿Cómo iba a conocer que ni siquiera Ibn al Qutiyya, el supuesto descendiente de Witiza, transmitía recuerdos familiares o que sus intereses eran opuestos a los de la realeza goda que padeció el avance del Islam? (Maíllo Salgado, 2009: 101-102). Desaparecidos tempranamente cuando la revolución abasí los archivos de Damasco, Oriente apenas retuvo cuentos y tradiciones distorsionados, de modo que lo poco aprovechable remite siempre a «libros cristianos» perdidos o rehechos, del tipo que manoseó y expurgó precisamente el círculo erudito de Alfonso III. ${ }^{2}$

Por fortuna, mientras dibujaba los primeros álbumes nunca dejé de leer las novedades investigativas e incluso comencé a indagar y escribir por mi cuenta, de forma que, a partir del álbum séptimo, el resultado me parece todavía honroso. Y fue merced a hallazgos

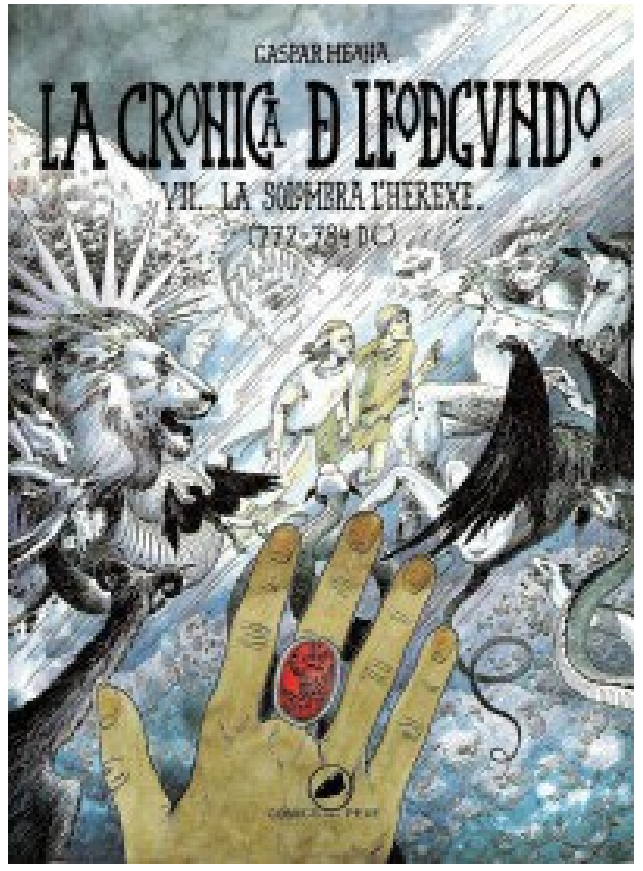

La Sombra l'herexe [772-784 d. C.] (El Cantar de Teaudán), Gaspar Meana verdaderamente providenciales como el artículo de Juan Gil (1978), al que lvego siguieron otros no menos decisivos, ${ }^{3}$ que me abrieron los ojos al tremendo peso que tuvo el temor al Fin del Mundo o a formar parte de la servidumbre

2. Hasta el gran al-Razi confesó que sus noticias más fidedignas para la conquista procedían de textos cristianos. Véase Crónica del moro Rasis, Madrid, Gredos, 1975, p. 348.

3. Veáse Vázquez de Parga, Luis (1971), «Algunas notas sobre el Pseudo Metodio y España», Habis, 2, pp. 143-164; 1971; Gil, Juan (1978-79), «Judíos y cristianos en Hispania (s.VIII-IX)», Hispania Sacra, XXXI.61, pp. 9-88; o Díaz y Díaz, Manuel Cecilio (1970), «Los textos antimahometanos más antiguos en códices españoles», Archives d'histoire doctrinale et litteraire du Moyen-Age, 37, pp. 151-168. 
de Anticristo en la atribulada cristiandad de las últimas décadas del siglo VIII y primeras del IX. Ello me forzó a leer y releer las plúmbeas obras completas de Beato de Liébana ${ }^{4}$ o de Elipando de Toledo ${ }^{5}$ o los poemas de Teodulfo de Orleans, ${ }^{6}$ literatura coetánea de los hechos que pretendía novelar que enriqueció notablemente el guion de los dos últimos tercios de mi cómic con un sesgo apocalíptico fuerte y creciente que a día de hoy considero uno de mis mayores aciertos, porque me llevó a entender que el reinado de Alfonso II —que en última instancia es el período de más peso en toda la obra-, estuvo presidido por el temor escatológico. En efecto, fue precisamente la inmersión en las fuentes literarias de la época no precisamente historiográficas, lo que me permitió introducir mayor verosimilitud en la trama argumental porque la familiarización con la maledicencia partidista vertida sobre los adversarios en cartas, poemas o tratados polemistas me llevó a la percepción de que difícilmente ese tono injurioso podía haber dejado de impregnar también a las crónicas y, en definitiva, de que nadie debería leer los textos altomedievales sin computar que la teología política en aquel tiempo fue un arma poderosa capaz de movilizar ejércitos, usada a destajo y sin miramientos. Me refiero a que no podemos pasar por alto que para un monje de aquellos siglos un «tiempo» era un año, o a que al número 7 se le solía asignar sin excepción el valor simbólico de totalidad o plenitud (Fernández Ramos, 1993: 62 y ss.); que no deberíamos ignorar que a los ladrones de ganado no se los castigaba sacándoles los ojos, pero sí a los ladrones de tronos, ${ }^{7}$ o que tras la calificación de «siervos» a los protagonistas de una rebelión podría ocultarse el enojo de los regicidas por la desobediencia de los deudos de su víctima. ${ }^{8}$ En estos y en otros casos parecidos aunque cueste creerlo todavía a día de hoy los historiadores racionalistas siguen cayendo en los ardides truculentos de los propagandistas altomedievales, pero será difícil que lo admitan, para desgracia de todos.

Así, merced a esta profundización creciente en la mentalidad de los protagonistas, llegó este autor a percibir que fue ya en los últimos años de vida de Alfonso II cuando comenzó a fraguarse la caída de sus verdaderos herederos y la de sus principios legitimizadores, y ello me permitió trazar en los últimos capítulos una reconstrucción convincente de las razones y acontecimientos que condujeron al cambio de régimen, lo que nos lleva al terrible Ramiro Bermúdez, un vengador crudelísimo que supo lavar su imagen y justificar sus muchos crímenes.

La percepción que transmiten las biografías de Ramiro I en las tres crónicas del ciclo historiográfico de Alfonso III merced a sus puntos comunes es la de que todas son deudoras de un relato trazado con inmediatez a su deceso, una «necrológica» escrita por los ideólogos de su reinado que constituye un

4. González Echegaray, Joaquín, Alberto del Campo y Leslie G. Freeman (eds.) (1995), Obras completas de Beato de Liébana, Madrid, Estudio Teológico de San Idelfonso-Biblioteca de Autores Cristianos.

5. Del Cerro Calderón, Gonzalo y José Palacios Royán (eds.) (2002), Obras de Elipando de Toledo, Toledo, Diputación Provincial de Toledo.

6. Alexandresco, Nikolai A (1970), The Poetry of Theodulf of Orleans, Tulane University, Ph.D. Thesis.

7. Para comprobarlo no hay como leer el Liber iudiciorum (El libro de los juicios, Madrid, BOE, 2015).

8. Me refiero a la escueta biografía del rey Aurelio en la Crónica Albeldense (véanse las Crónicas Asturianas, ed. cit.). 
unicum entre las semblanzas de sus predecesores y sucesores precisamente por su fuerte sesgo apocalíptico, lo que sugiere que fue la instrumentalización de las profecías del Fin del Mundo lo que permitió al golpista acreditar la deposición del rey legítimo y la masacre de los Pelágidas, advertencia que me condujo a colegir que Santa María de Naranco, la obra arquitectónica cumbre del período había sido trazada y construida a toda prisa como colofón explicativo de su mandato porque todos los motivos escultóricos que la decoran concuerdan con la ideología escatológica triunfal que impregna la trayectoria de su comitente en las crónicas. Que la arquitectura sirviese para legitimar a un golpista no era ninguna novedad, pero no estábamos ante un mero arco conmemorador de victorias humanas sino divinas, un recinto evocador de la terrible justicia de Cristo al Fin de los Tiempos, y entonces el objetivo del rencoroso revolucionario y de sus artistas no se habría limitado a instrumentalizar el concepto de virga iustitia, ${ }^{9}$ sino que habrían pretendido justificar en todos sus extremos su sanguinario desquite, amparándose en una lectura tendenciosísima de las desgracias recientes, las que le sirvieron de trampolín al poder en la capital.

Llegar a esta percepción es la mayor satisfacción que me han proporcionado mis años de trabajo en torno a la Crónica de Leodegundo sin duda alguna, pues supuso desvelar que la misteriosa Santa María de Naranco se concibió como el Trono desde el que el Señor impartiría sentencias tras su Parusía, un trono para salvar y condenar y un patíbulo terrible, algo inimaginable para cuantos nos habíamos venido dejando engañar por las excelsas proporciones de este juzgado reconvertido en iglesia que nunca fue un belvedere lúdico e inocuo pese a su entorno bucólico. Quienes lo pongan en duda y deseen sopesar si estoy en lo cierto podrán acceder a mi intento de demostración en las notas de autor del último volumen en la edición de la Universidad de las

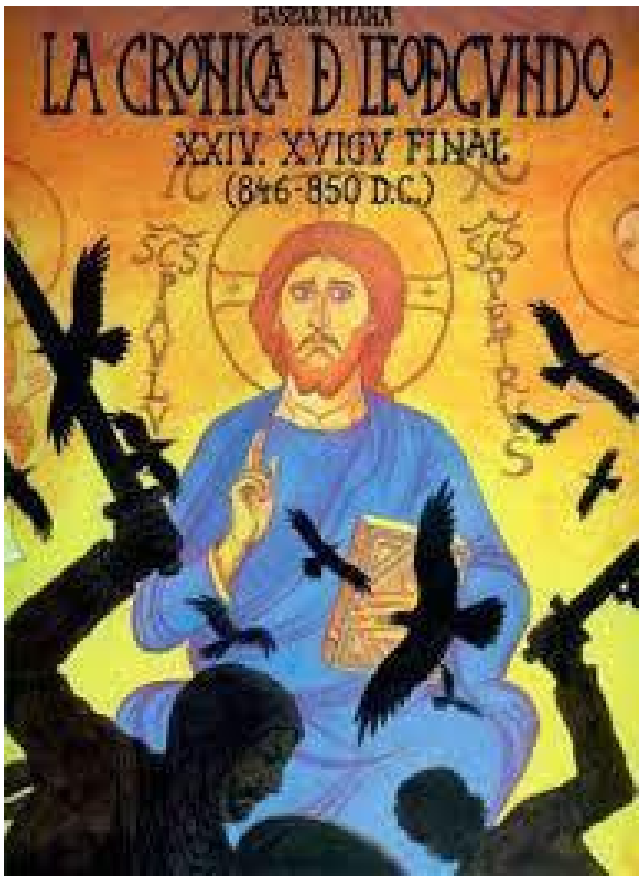

Xuiciu final [846-850 d. C.], Gaspar Meana Islas Baleares (2016). ${ }^{10}$

\footnotetext{
9. Referencia a la virga ferrea del salmo n. ${ }^{\circ} 2$, que advertía a cuantos se alzasen contra el ungido del Señor, pero también a los «rectores de la tierra» que no sirviesen a Dios con temor. Incumbe también en nuestro contexto al instrumento con el que el general de las cohortes Angélicas, Miguel, derrotará al demonio y a Anticristo. Recuérdese que en las ilustraciones de los «Beatos» el arcángel aparece siempre alanceando a la Serpiente.

10. Gaspar Meana, La Crónica de Leodegundo. Vol. 5: El Cantar de Piniol (II) (844-960 D. C.). Universitat de les Illes Balears, 2016: "Un nuevo Constantino contra un nuevo Majencio: la justicia del río Narcea», pp. 59-65; «己̇Pudo tener Oviedo bajo Nepociano un destino más halagüeño que Sevilla el año 844?», pp. 117-121; «Un palacio desde el que la justicia de Ramiro I podía pasar por divina...., pp. 176-187; «Sobre un héroe y felón que nunca debió ser olvidado», pp. 189-202; «Sobre la Tau de Scemena», pp. 203-21 1; "Un "juego de tronos" en Naranco: Cristo y su campeón en un mismo solio», pp. 213-231; «Sobre el ocaso de un trono temible y desafiante», pp. 283-287; «Sobre el enclave en el que pudo apetecer reposo Ben Bermud, el inconformista sobrino de Alfonso Ilı, pp. 289-295.
} 
Fue precisamente mientras estudiaba "el arte de la venganza» que patrocinó el hijo ilegítimo de Bermudo el diácono cuando comencé a maliciar que había un paralelismo vital entre este sobrino indeseado y heredero postergado de Alfonso Il y el sobrino que ciertos romances antiguos llaman Bernaldo. A la larga me convencí de que eran ciertas las sospechas de que en ellos retenemos un mínimo resto de un antiquísimo cantar de gesta (Menéndez Pidal, 1973: 63 y 237), " y de que este personaje semiolvidado y denostado, obsesionado por la vindicta paterna y por su legitimidad, en realidad no había pretendido otra cosa que heredar a su propio progenitor. A la postre, este personaje ya no tan legendario que debió vivir semiexiliado entre el sur de Lugo y el Bierzo, ${ }^{12}$ y que muy bien pudo ser conocido popularmente en esas fronteras del reino como Ben Barmud, habría aprovechado la irrupción normanda para «salirse con la suya», llevándose por delante a su hermano de madre Aldroito y a su coronado padrastro Nepociano. ${ }^{13}$ Pero ni quiero ni debo extenderme en este espacio que se me regala. De todo esto he dado cuenta en las notas de autor enumeradas en la nota 15, lo que me lleva ya, para finalizar, al apartado de los agradecimientos.

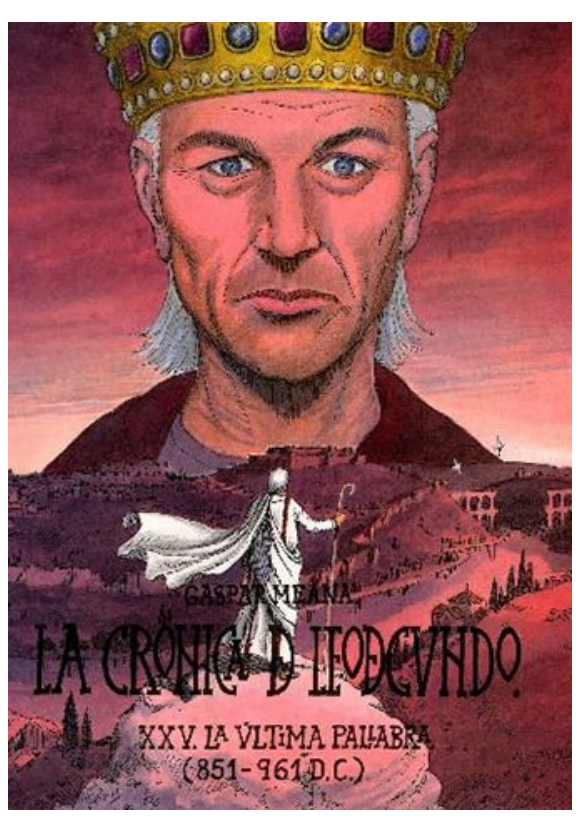

La última pallabra [850-960 d. C.], Gaspar Meana

Nunca le estaré suficientemente agradecido a Florentino Flórez Fernández y a Faustino Rodríguez Arbesú por su ayuda y mediación para la edición de mi obra o al Servicio de Publicaciones de la Universidad de las Islas Baleares por facilitarme la inclusión de todas las notas aclaratorias que juzgué conveniente incluir. Además, gracias a ellos me fue posible introducir pequeños cambios en el guion para reforzar su sentido interno, como la supresión de algunas menciones a Bernaldo anteriores a su identificación con el rey Ramiro I o como la introducción de cuatro nuevas planchas en el volumen 2 para avanzar sobre mis investigaciones inéditas la reclusión voluntaria del exiliado Alfonso II en el monasterio de Aniano (y no en el inexistente de Abelania), ${ }^{14}$ al amparo del famoso e influyente abad Benito/Witiza (Andenna y Bonetti, 1993).

11. Acerca de la mención de «Bernardo» en la Crónica General de Alfonso X entre los cantares de gesta, véase Clavero, Dolores (1994), Romances viejos de temas épicos nacionales. Relaciones con gestas y crónicas, Madrid, Ediciones del Orto, p. 29.

12. La consideración del conde del Bierzo Gatón como hermano de Ordoño I por Ibn Idari (al-Bayan, trad. Fagnan, II, p. 154), dudosa para algunos, se refuerza con el hecho de que le pusiera a un hijo suyo el nombre de Bermudo, porque ello vendría a ser un homenaje a su abuelo Bermudo I. Las raíces de todos ellos entre el Bierzo y el sur de Lugo vendrían a demostrarse con su donación a un monasterio próximo de la villa ranimiri que bien pudiera haber sido la base de operaciones del futuro golpista durante sus años de su alejamiento de Oviedo.

13. La Crónica de Leodegundo apuesta por la posibilidad de que el diácono Bermudo hubiese engendrado a Ramiro en la hermana de Alfonso II durante su exilio antes de que este le adjudicase su mano a su cuñado Nepociano; con ello habría seguido el ejemplo de Alfonso I y Silo, que reinaron en Asturias merced a sus uniones con sendas princesas Pelagidas: Ermesinda y Adosinda.

14. No existe memoria local alguna sobre un monasterio llamado «Abelanie/Abelian» (Crónica Albeldense, XV, 9). 
Y es que en realidad después de que terminara el guion y los dibujos del comic que comentamos nunca dejé de investigar sobre la Alta Edad Media hispana alternando esas pesquisas con mi trabajo como ilustrador. Esa época me ha procurado tanto solaz y preocupaciones y me ha ocupado tanto tiempo como mi propio siglo, y a estas alturas de mi existencia me parece tan vívida como la mía. A veces pienso si no habré vuelto a nacer para hacerle justicia a seres queridos de antaño y en esos momentos llego a imaginar que tengo en común con Leodegundo mucho más de lo que sería conveniente. Pero de mi cordura no estoy obligado a dar razón. Laus deo... y a ustedes que leen.

Gijón, las Quintanas, a 13 de mayo de 2021

\section{Bibliografía}

Andenna, Giancarlo y Cinzia Bonettı, Benedetto di Aniane. Vita e riforma monastica, Milano, San Paolo Edizioni, 1993.

BronisCh, Alexander Pierre (2009), «ldeología y realidad en la fuente principal para la Historia del Reino de Asturias: el relato de Covadongai», en Cristianos y musulmanes en la Península lbérica: la guerra, la frontera y la convivencia, Ávila, Fundación Sánchez-Albornoz, pp. 69-110.
Fernández Ramos, Felipe (1993), Los enigmas del Apocalipsis, Salamanca, Universidad Pontificia.

GIL, Juan (1978), «Los terrores del año 800», en Actas del Simposio para el estudio de los códices del Comentario del Apocalipsis de Beato de Liébana, Madrid, Joyas Bibliográficas, vol. I, pp. 217-247.

Maíllo Salgado, Felipe (2009), De historiografía árabe, Madrid, Adaba.

Menéndez Pidal, Ramón (1973), La épica medieval española desde sus orígenes hasta su disolución en el romancero, vol. XIII, Madrid, Espasa-Calpe, pp. 63 y 237.

MeanA, Gaspar, «Un deber de vindicta que atraviesa los siglos. La crónica de Leodegundon, Storyca 3 (2021), pp. 5-11. 